\title{
Report of the Tobacco Policy Research Study Group on Tobacco Products
}

\author{
John Slade, Gregory N Connolly, Ronald M Davis, Clifford E Douglas, Jack E \\ Henningfield, John R Hughes, Lynn T Kozlowski, Matthew L Myers
}

\section{St Peter's Medical Center, UMDNJ- Robert Wood Johnson Medical School, New Brunswick, New Jersey J Slade \\ Massachusetts \\ Department of Public Health, Boston, Massachusetts G N Connolly}

Michigan Department of Public Health, Lansing, Michigan R M Davis

Advocacy Institute, Washington, DC C E Douglas

National Institute on Drug Abuse, Baltimore, Maryland J E Henningfield

University of

Vermont, Burlington, Vermont

J R Hughes

Pennsylvania State University, University Park, Pennsylvania L T Kozlowski

Asbill, Junkin, and Myers, Chtd, and the Coalition on Smoking or Health, Washington, DC M L Myers

Correspondence to: Dr John Slade, Department of Medicine, St Peter's Medical Center, 254 Easton Avenue, PO Box 591, New Jersey, New Brunswick, New Jersey 08903-0591, USA.
Nicotine is the active pharmacological agent in tobacco products. ${ }^{1,2}$ The interaction of this alkaloid with nicotinic receptors in the central nervous system is the pharmacological basis for its addictive qualities. The chemical dependence regularly produced by nicotine results in prolonged exposure to the many toxic materials found in tobacco and tobacco smoke. ${ }^{3}$ These exposures lead, in turn, to the burden of illness and death caused by tobacco. ${ }^{4}$

A major underlying problem with tobacco products is that their production and use became entrenched in the US economy and society well before their dangers were understood. As a result the industry has, with only limited exceptions, been able to block federal legislative and regulatory actions that would otherwise have been brought to bear on such toxic products (see appendix).

This paper summarises existing knowledge about tobacco products in the United States relevant to regulatory issues, discusses questions for policy research in this area, and proposes a research agenda to advance public policy. The major objective of this research agenda is to support increased regulation of tobacco products.

\section{Background}

[W]e would like you to think of Research and Development as an originator, developer, and tester of the technological weapons system that underlies and protects company policies, particularly in the area of smoking and health. Obviously, without an adequate weapons system, strategy is severely limited... Our most important defensive weapons are in the category of product development. Here the company and industry are facing two clearly discernible trends, both of them arising from the smoking and health controversy. The first of these is the continuing demand to make cigarets (sic) milder and milder, in effect to lower the tar and nicotine delivery per cigaret... The second trend is the intensifying pressure to develop a "safe" cigaret. DIRECTOR OF RESEARCH, PHILIP MORRIS, in comments to the company's board of directors, mid-1970s

For nearly 40 years, major new product design and innovation in the tobacco industry seems to have been driven by a concern that new cigarettes should appear safe, or at least less hazardous than previous products, even if it was not possible to actually deliver on this promise. These innovations, along with the marketing and public relations efforts surrounding them, contributed to sustaining and, between 1954 and 1964, even increasing con- sumption rates. Many observers believe that the following innovations fostered the impression that a new product had a health advantage over the one it was designed to replace:

1950s: King size - promoted for "natural filtration"

1950s: Filters

1964: Low "tar"

1970s: Ultra low "tar"

1988: Premier

1989: "Low smoke," “de-nicotined," perfumed

Blatant health claims for filter cigarettes were common before the Federal Trade Commission (FTC) promulgated its advertising guidelines in $1955 . .^{5}$ (See appendix) For instance, Kent cigarettes, which used crocidolite asbestos as the filtering agent from 1952 until at least 1956, promised "health protection" as a result of its Micronite filter. ${ }^{6}$ Premier was a nicotine delivery system which, while it superficially resembled a cigarette, burned a charcoal fuel element to heat beads that had nicotine and glycerine on their surface. ${ }^{7-9}$ Puffing a lit Premier produced an aerosol consisting mostly of nicotine, water, glycerine, carbon monoxide, and carbon dioxide. Promoted as a "cleaner smoke" by R J Reynolds, it failed in test markets and drew much criticism from medical and public health groups. The critics maintained that Premier should be regulated as a drug by the Food and Drug Administration (FDA) and meet the standards of the Food, Drug, and Cosmetic Law before being marketed. The agency had not reached a final determination concerning the regulatory state of this product under that statute when the product was withdrawn from the market.

The moist snuff category has also seen major innovations, especially in the series of products designed with a "graduation strategy" in mind, taking a novice user from Skoal Bandit to regular Skoal to Copenhagen with increasing nicotine and decreasing sweetness at each step. ${ }^{10}$ The first product in the sequence is packaged in unit dose sachets. A major theme for the starter product emphasises the reduced hazard of moist snuff compared to cigarettes: "Take a pouch instead of a puff."

These innovations have always appeared in the setting of rising concerns about the toxicity of smoking, but products have achieved far more significant public relations and marketing gains than improvements in public health. The 
reduced emission cigarettes are associated with modest reductions in risk of cancer, but the gains are far less than the numbers that comparisons from machine-based emissions would suggest, probably because of differences in how these cigarettes are smoked. ${ }^{4,11}$ For instance, blocking the vent holes in filters of many "low tar" brands dramatically increases nicotine and carbon monoxide yields. ${ }^{12}$ Furthermore, the average "tar" yield for cigarettes in the United States has been stable since 1979 , after a period of steady decline. ${ }^{13}$ The risk of heart disease, which is virtually tied with lung cancer as the leading category of fatal complication from smoking, is undiminished among people who smoke "low yield" brands. ${ }^{14,15}$ Compared with abstinence, all cigarettes have unacceptably high risks of causing illness and death when used as intended.

Under the Food, Drug, and Cosmetic Act, the manufacturer's intent with regard to altering the structure or function of the body or its intent with regard to treating, mitigating, or preventing disease are major factors that the FDA considers in determining whether a particular product is a drug. Manufacturers of tobacco products have, for the most part, avoided expressing intentions about their products in ways that have attracted regulatory action. Many in public health circles, however, believe innovative products introduced since the early 1950s deter people from stopping by seeming to provide a seemingly safer alternative to a person's current brand. Despite this, products based on these innovations have avoided regulation by what many believe is an elaborate charade and word game. Whereas many observers believe that advertising terms such as "satisfaction," "filter-tipped," "slims," "thins," and "low tar" have connotations for the public that place these products in the arena of products intended to exert pharmacological effects (relief of nicotine withdrawal) and to mitigate or prevent disease, the manufacturers have argued otherwise.

Many smokers look on their smoking as an addiction, ${ }^{16-18}$ and this perception has broad implications for understanding the manufacturer's intent in marketing these products. Similarly, most people who smoke are concerned about potential complications of smoking. ${ }^{4}$ The ways efforts at marketing and public relations help customers minimise these concerns contributes to an understanding of the manufacturer's intent. The reassuring atmosphere produced by the entire marketing and public relations efforts of the industry needs to be considered as well as the specific language and imagery of individual advertising campaigns. The long running slogan for Newport, "alive with pleasure," is an obvious example of an image garishly mocking of the actual outcome for nearly a third of the brand's most loyal customers.

Important data on manufacturer's intent in these regards have emerged from tobacco product liability litigation. ${ }^{19,20}$ Taken as a whole, these data suggest not only intent to promote cigarettes as acceptably safe, but a conspiracy among the various companies to accomplish this beginning in the mid-1950s and continuing to the present. For instance, Federal Judge $\mathrm{H}$ Lee Sarokin, in ruling on the defendant tobacco companies' motion for a directed verdict in the Cipollone case, noted that:

the evidence presented ... permits the jury to find a tobacco industry conspiracy, vast in its scope, devious in its purpose and devastating in its results. The jury may reasonably conclude that defendants were members of and engaged in that conspiracy with full knowledge and disregard for the illness and death it would cause. ${ }^{21}$

The findings from discovery and testimony presented at trial in these lawsuits, however, have yet to be fully analysed, extended, and applied in the context of product regulation.

Innovative products, even ones that might actually cause fewer adverse health consequences for people who do not want to stop smoking, are not sold in ways that restrict them to those customers who are committed to continuing to smoke. With undiminished force and intensity, innovative products also reach novices, people interested in stopping smoking, and former smokers. These three groups, which actually determine the overall size of the cigarette market over time, have been overlooked in most public health analyses of innovation in the tobacco industry. ${ }^{22}$

The importance of novices, potential stoppers, and former smokers, though, is easily appreciated by considering the following:

Novices. New smokers are needed to replace those who die or who have stopped. The market for cigarettes is strikingly dynamic: over half of current smokers have begun to smoke since the publication of the first Surgeon General's Report in 1964. About $70 \%$ of teenagers experiment with cigarettes at least once.

Potential quitters. Seventy five per cent of people who smoke want to stop smoking, and a third try to do so each year.

Former smokers. Nearly half of all men in the United States who have ever smoked regularly have already stopped smoking; however, relapse is not uncommon and may occur years after stopping.

The central problem in regulation of tobacco products is that the product itself is not regulated in ways that provide substantial protection to the public. The existing warnings are widely regarded as ineffective. ${ }^{23-26}$ There has been no requirement that ingredients, such as flavourings, humectants, temperature control chemicals, and paper treatments be listed $^{27}$; furthermore, there is no requirement that ingredients be shown to be safe for human consumption. There are no federal requirements for ceilings on "tar" deliveries such as those now in effect in Egypt and Finland, ${ }^{28}$ under final development in China, and proposed for the European Community. ("Tar" ceilings may be more important for public health in developing countries where average "tar" levels are far higher than in markets such as the United States. At a certain level of "tar" reduction, cigarettes become unaccept- 
able to consumers. ${ }^{29}$ ) Importantly, with few exceptions (for instance, Trim, Premier, Favor, and N-Bloctin/Sprectra), Innovations in tobacco products that seem to respond to health concerns have not received the level of governmental scrutiny expected of other product categories that affect health in important ways. The federal regulatory agencies have been largely hemmed in by various Congressional and court actions in this arena (see appendix).

From time to time, the FDA has asserted jurisdiction over particular tobacco products as drugs when the agency believed that the manufacturer had made claims showing intent to exert a pharmacological effect or to have a therapeutic effect on the consumer. Examples of these actions include Trim, Fairfax, Favor, and $N$-Bloctin/Sprectra. ${ }^{30-32}$ In one instance, the FDA determined that a tobacco product was a food (a chewing gum) adulterated with tobacco (Masterpiece Tobacs). ${ }^{33}$

In summary, although the pharmacology of nicotine and the toxicology of tobacco smoke are well known, showing intended use as a "drug" under the existing Food, Drugs, and Cosmetics Act represents another matter entirely. Important gaps in knowledge and understanding of this area are outlined next.

\section{Research needs}

TOBACCO PRODUCTS

Data are needed to support regulation of tobacco products. Especially useful would be achieving a better understanding of the relation between tobacco product innovation and the rates at which people stop smoking.

\section{Analysis of existing data}

A comprehensive review of existing information about tobacco products from a policy perspective would inform regulators about the origins of specific products now on the market and about the regulatory climate in which certain conventions in the industry developed. For instance, health claims in cigarette advertising were regulated by the Federal Trade Commission (FTC) as early as the 1930s, and a thorough review of this past experience may contribute to an understanding of current marketing practice. The analysis should include reviews of:

- Terminology used in advertising, packaging, brand names, etc including the history of such code words as "satisfaction", "pleasure", "taste", "low tar", "thin", "slim", "light", and "clean". These terms are part of a restricted and carefully developed vocabulary seemingly designed to avoid regulation while implying a variety of drug-like benefits for tobacco products

- Industry sponsored research into alternative designs for tobacco products. An enormous effort has been devoted to the development of products that seem less hazardous, but only a fraction of such effort has led to successfully introduced new products. Improved knowledge about the entire research effort should help inform regulators about the intent behind new products that have been marketed

- Patents, trade publications, filings with the Securities and Exchange Commission, scientific publications, etc

- Regulation of tobacco products in Europe and elsewhere

- Additives

- The Adult Use of Tobacco Survey, conducted by the US Centers for Disease Control, and other surveys contain data on brand switching patterns. These should be analysed to ascertain relations between brands smoked and health concerns about smoking

- Examination of relevant documents, depositions, and trial transcripts from product liability suits

- Past regulatory efforts and court decisions. In the mid-1950s, the FTC attempted to regulate cigarette advertising as drug advertising so that it would have injunctive power. A court ruling against this approach hampered FTC activities and may have led to the agency's proposal of a set of voluntary advertising guidelines in September 1955. This court case might be re-examined in the light of current understanding of the pharmacology of nicotine and the central role this agent has in the use of tobacco

- Cross-cultural studies - namely, experience in other countries with product innovation and regulation.

\section{Analysis of new products}

Innovation is a continuous process in the industry. New products appear regularly. Among recent innovations introduced or under test are "low smoke", "de-nicotined", and designs incorporating an air freshener. Even apparently minor changes, such as Marlboro Medium and Winston Select, have potentially important implications in the marketplace and should be examined and understood from a public health perspective as soon as possible after they are announced. As well as health concerns, appeals to weight control have long been part of cigarette design and marketing, and these themes are evident today. New products should be examined continuously as they appear for: tives

Design and formulation, including addi-

- Labelling, advertising claims, and public relations associated with a product: What is the targeted market? Does the labelling or other material make explicit or implicit health claims?

- Examinations of test markets for new tobacco products and for new advertising campaigns as well as comprehensive reviews of regular marketing programmes. Increasingly, tobacco product marketing relies on ephemeral promotions such as point of purchase displays and give away items. Unless data are gathered in the field at the time that the actual marketing effort is going on, potentially important information relevant to conclusions about labelling and a manufacturer's intentions will be lost 
- Performance in the laboratory on standard tests including tests of emissions and of propensity to ignite upholstered furniture

- An assessment of toxic and addictive potential and of the market niche

Results of these ongoing analyses should be made available to the public and to appropriate governmental agencies.

The public's expectations and misconceptions about tobacco products

When people buy "low tar" cigarette brands, what are their intentions, if any, about protecting their health? When women buy a "slim" cigarette brand, what are their intentions, if any, about smoking to lose weight or avoid weight gain? To what extent are cigarette brands that do not explicitly emphasise weight control themes used for this purpose? Does the advertising message of brands that emphasise weight control create consumer perceptions that other brands are useful in helping to control weight as well?

New studies are needed, extending proposed analyses of the Adult Use of Tobacco Survey, of brand switching behaviour $v$ self reported concerns about smoking (including addiction, harm to others, weight control, and medical complications), complications from smoking already experienced, and advice about smoking received from various sources. The hypothesis would be that people who have greater concerns about health or weight control, who have experienced more complications, or who have received more urgings to stop smoking are more likely to smoke brands perceived as less hazardous or as offering weight control. Studies of this sort would complement focus group research or cross sectional surveys of attitudes towards the brands themselves.

Also, focus group research, and to a lesser extent, population surveys, should be conducted regularly to see how various tobacco products and communication techniques are received by the public. This work must be sensitive to the subtleties of the communication techniques that tobacco companies have developed over time, and it should be ongoing. An important difficulty with these studies may be the degree to which people censor their thoughts about whether their cigarette brand seems "safer" to them or not. Whereas most people say they believe their brand of cigarette is at least as hazardous as other brands, between a fourth and fifth of current smokers report thinking that the kind of cigarette they smoke is less hazardous than other brands (Adult Use of Tobacco Survey, summarised in 1989 Surgeon General's Report, page 181). ${ }^{4}$ A larger number behave as if this is what they are thinking, because smokers of "light" cigarettes make up more than half of the market, and advertising emphasises "low tar" as an advantage. Various subgroups of the public should be sampled, especially people at the margins of the market; novices, people who want to stop smoking, and the recently abstinent.

Research examining the degree to which people use apparently less hazardous products as an alternative to stopping smoking should be an especially high priority. For example, how do the frequency and intensity of attempts to stop compare between people who smoke "low tar/low nicotine" brands and people who smoke higher yield brands? Also, studies on the extent to which "low tar/low nicotine" brands function as starter products or are preferentially used by those who relapse from abstinence would be helpful.

\section{Additives}

Tobacco companies use a wide variety of additives in their products. The contribution of these additives to the toxic and addictive properties is not clear. Nicotine itself is one of these additives. ${ }^{34}$ Tobacco product manufacturers have disingenuously described added nicotine as a flavourant, or, simply, as tobacco, because the nicotine used is extracted from tobacco. The amount of nicotine added, the purpose of supplementing tobacco blends with nicotine, and related questions are all of interest in tobacco product regulation. Research on additives should consider pyrolysis products as well as the materials themselves.

Beyond learning more about the additives themselves, research can help regulators to choose among the policy alternatives implied by additives (ignoring them; requiring disclosure of additives on advertisements, packages, or package inserts; banning one or more of them). Relevant data would include survey and focus group research on how various regulatory approaches would affect behaviour in the marketplace and analysis from a toxicological and an addiction perspective on what public health benefits might accrue from various approaches. Among the issues to explore would be whether listing ingredients is perceived as indicating government approval of the product as safe. Such studies should, of course, also be conducted after the implementation of any new regulatory approach as well as to see if the regulation has had the desired effect. In the United Kingdom, there is a list of approved additives for cigarettes. What have been the results of this approach?

\section{Alternative labelling}

Little research has analysed the public's perceptions of existing labels. This work needs to be extended and amplified for its implications for new labelling strategies. ${ }^{35}$ The experience in Canada, Sweden, Iceland, the United Kingdom, Australia, and elsewhere with more visible, simpler warning labels and package inserts should be examined for its public health value. ${ }^{36}$ These strategies as well as other approaches to labelling should be considered in the design of an optimal system of warnings for packaging of tobacco products. For instance, would it be helpful to disclose the cyanide and benzene content of cigarette smoke? Should a package insert include a free phone number for help to stop smoking? What is the health benefit to the public of a specific warning about liability to addiction or the risk of death from smoking? Once again market 
research, before and after changes such as these, would be most helpful in designing and refining public health strategy and policy.

"Tar" ceilings

The experience in Finland and Egypt, and the anticipated experience in the European Community and China with "tar" ceilings should be followed up closely and research conducted to see how these policies affect the marketplace and public health. Particular attention should be paid to exploring the potential for this approach in countries where cigarettes with higher than average delivery of "tar" are prevalent.

\section{Conclusion}

Although all tobacco products are toxic when consumed as intended by their manufacturers, they are subject to little regulation. This situation exists for various historic, political, and economic reasons. The current understanding of use of tobacco as a form of addiction provides a framework for a renewed effort at the regulation of these products. Policy development in this area will be facilitated by research along the lines we have suggested. The areas that should receive the highest attention include:

- Analysis of existing data

- Analysis of new products as they are marketed or tested

- Examination of the public's expectations about tobacco products and its behaviour in the use of new products

- Characterisation of additives to tobacco products

- Examination of alternative labelling for tobacco products

- Consideration of the possible benefits of establishing permissible ceilings for "tar" content.

For the most part, people use tobacco to ingest nicotine. Along with nicotine, they ingest a huge variety of toxic substances. Regulations commensurate with the seriousness of this problem are conspicuously lacking. This research agenda should be of assistance in developing the necessary regulatory approaches.

\section{Appendix}

HEMMED-IN REGULATORS

The deck is stacked against federal regulatory agencies when it comes to dealing with tobacco products. ${ }^{4}$ None has been in a position to treat tobacco like the other dangerous products for which it has responsibility. The tobacco industry has long protected its interests in Washington by skilful lobbying and public relations, often centred around the Tobacco Institute, which was established in the 1950s. The authority of the potential regulators has been sharply circumscribed by law or by political pressure. Key agencies with potential regulatory power in this arena are:
The Food and Drug Administration (FDA)

The FDA has only become involved in regulating tobacco products on a case by case basis, when overt promotions for specific products have made health claims. ${ }^{4}$ It has refrained from asserting jurisdiction over all tobacco products, and it even successfully fought off a citizens' petition in the 1970s that asked FDA to regulate cigarettes as drugs. ${ }^{37}$ Some observers think that, were the FDA to declare all tobacco products to be drugs under the law, it would have to order them off the market because none are of established safety. Approaches short of this within the current structure have been proposed, ${ }^{11,38,39}$ and a bill now before Congress would establish special, specific, limited authority within FDA for tobacco products which get around this limitation, but this bill faces an uphill battle. ${ }^{35}$

The Federal Trade Commission (FTC)

The FTC has broad authority to oversee advertising, centred around its responsibility to ensure that marketing efforts are not false or misleading. For over 20 years, starting in the 1930 s, the agency took an active role in challenging numerous excesses of cigarette advertising. ${ }^{5}$ In the mid-1960s, the Commission proposed mandatory warning labels, and when it seemed likely that the Commission would act, the Congress passed a law preempting FTC action, which specified the language to be used in warning labels. All subsequent revisions of labelling requirements have been the product of lengthy negotiations in Congress as well. Except for a brief period in the late 1970s, the FTC has been notably tolerant of advertising of tobacco products for the past 20 years. Although the Commission has a permanent professional staff its members are Presidential appointees.

\section{The Consumer Products Safety Commission (CPSC)}

The enabling legislation for the CPSC excluded tobacco and tobacco products from the definition of "consumer product". When it was formed in 1972, the new agency was given jurisdiction over the Federal Hazardous Substances Act (FHSA), which had previously been administered by FDA. The FHSA included tobacco in its purview. When the American Public Health Association petitioned the Commission to set a ceiling for tar delivery under the FHSA, the Commission declined to act, citing lack of jurisdiction. A federal court ruled that the Commission did, indeed, have jurisdiction, and ordered the CPSC to consider the petition. At this point, Congress amended FHSA to exclude tobacco and tobacco products from the definition of hazardous substances.

\section{The Bureau of Alcohol, Tobacco, and}

Firearms $(B A T F)$

The mission of BATF has been the regulation of taxation of tobacco products. The agency reviews cigarette packaging and marketing to 
ensure that they do not involve lotteries and that they contain no indecent or immoral words, pictures, or other representations. It enforces the contraband cigarette act that helps reduce large scale bootlegging of cigarettes across state borders in instances where sizeable tax differentials exist.

1 US Department of Health and Human Services. The health consequences of smoking : nicotine addiction. A report of the Surgeon General, 1988. Atlanta, Georgia: Centers for Disease Control, Office on Smoking and Health, 1988. (DHHS Publication no (CDC) 88-8406.)

2 US Department of Health and Human Services. Nicotine dependence. In: US Department of Health and Human Services. Drug abuse research: the third triennial report to Services. Drug abuse research: the third triennial report to
Congress from the secretary, Department of Health and Congress from the secretary, Department of Health and stitute on Drug Abuse, 1991: 213-42. DHHS Publication No (ADM) 91-1704.)

3 Henningfield JE, Cohen C, Slade J. Is nicotine more addictive than cocaine? Br $\mathcal{f}$ Addict 1991; 86: 565-9.

4 US Department of Health and Human Services. Reducing the health consequences of smoking: 25 years of progress. A report of the Surgeon General, 1988. Atlanta, Georgia Centers for Disease Control, Office on Smoking and Health, 1989. (DHHS publication No (CDC) 89-8411.)

5 Committee on Government Operations. False and misleading advertising (filter-tip cigarettes). Hearing before a Subcommittee of the Committee on Government Operations. Subcommittee of the Committee on Government Operations.
House of Representatives. Fuly 18, 19,23,24,25, and 26, House of Representatives. Fuly 18, 19, 23, 24, 25, and 26,
1957. 85th Session, Washington, DC: US Government 1957. 85th Session,
Printing Office, 1957.

6 Slade J. The tobacco epidemic: lessons from history. $\mathcal{f}$ Psychoactive Drugs 1989; 21: 281-91.

7 RJ Reynolds Tobacco Company. Chemical and biological studies on new cigarette prototypes that heat instead of burn tobacco. Winston-Salem, North Carolina: RJ Reynolds Tobacco Company, 1988.

8 Committee on Energy and Commerce. Health consequences of smoking: nicotine addiction. Hearing before the Subcommittee on Health and the Environment of the Committe on Energy and Commerce, House of Representatives. Fuly 29, 1988. Washington, DC: US Government Printing Office, 1988. (Serial No 100-168.)

9 Slade J. Rf Reynolds' “Smokeless cigarette': panacea or public health menace? Boston: American Public Health Association, November 1988. (Available as document number ED 311377 from ERIC, University of number

10 Connolly GN, Winn DM, Hecht SS, Henningfield JE, Walker B Jr. The reemergence of smokeless tobacco. New Engl f Med 1986; 314: 1020-7.

11 Warner KE, Slade J. Low tar, high toll. Am $\mathcal{F}$ Public Health 1992; 82: 17-8.

12 Kozlowski LT, Pope MA, Lux JE. Prevalence of the misuse of ultra-low-tar cigarettes by blocking filter vents. $A m \mathcal{J}$ Public Health 1988; 78: 694-5.

13 Federal Trade Commission. Report to Congress pursuant to the Federal Cigarette Labeling and Advertising Act, 1988. the Federal Cigarette Labeling and Advertising Act, 1988.

14 Palmer JR, Rosenberg L, Shapiro S. "Low yield" cigarettes and the risk of nonfatal myocardial infarction in cigarettes and the risk of nonfatal myocardial inf.

15 Benowitz NL. Health and public policy implications of the "low yield" cigarette. New Engl f Med 1989; 320 1619-21.

16 Henningfield JE, Clayton R, Pollin W. Involvement of tobacco in alcoholism and illicit drug use. $B r \mathcal{F}$ Addic 1990; 85: 279-92.

17 Eiser JR, van der Pligt J, Raw M, Sutton SR. Trying to stop smoking: effects of perceived addiction, attributions for failure, and expectancy of success. F Behav Med 1985; 8 : 321-41.

18 Gallup. Growing bias toward smokers: many American favour restrictions on smoking in public places. (Princeton, New Jersey: Gallup Organisation, 1990 (Gallup Report No 298.)

19 Press release. Incriminating cigarette industry documents released. Boston, Massachusetts: Tobacco Products released. Boston, Massachusetts:
Liability Project, 26 March 1988.

20 Daynard RA. Recent developments in tobacco litigation 1991. Tobacco Control 1992; 1: 37-45.

21 Cipollone $v$ Liggett Group Inc, CA 83-8846 (DNJ June 7 1988).

22 US Department of Health and Human Services. The health consequences of smoking : the changing cigarette. Washing ton, DC: Public Health Service, Office of the Assistan Secretary for Health, Office on Smoking and Health, 1981. (DHHS Publication No (PHS) 81-50156.)

23 Chapman S, Wilson D, Wakefield M. Smokers' understanding of cigarette yield labels. Med $\mathcal{F}$ Aust 1986; 145: $377-9$.

24 Davis R, Healy P, Hawk SA. Information on "tar" and nicotine yields on cigarette packages. Am f Public Health 1990; 80: $551-3$.

25 Myers ML, Iscoe C, Jennings C, et al. Staff report on the cigarette advertising investigation. Washington, DC: Federal Trade Commission, May 1981.

26 Richards R, Fischer P, Conner FG. The warnings on cigarette packages are ineffective. $\mathcal{F} A M A 1989 ; 261: 45$.

27 Chapman S. Come to where the flavour is... additives and pesticide residue in Australian cigarettes. Drug and Alcohol Review 1992; ii : 3-6.

28 Omar S, El Mallah F, Iskander Z. Ten years after legislation. In Durston B, Jamrozik K, eds. Tobacco and health 1990 - the global war. Perth, Western Australia: Health Department of Western Australia, 1990. (Proceedings of the seventh international conference on ceedings of the se

29 Kozlowski LT. Evidence for limits on the acceptability of lowest-tar cigarettes. Am f Public Health 1989; 79: 198-9.

30 Coalition on Smoking or Health. Petition to classify Rf Reynolds new alternative nicotine delivery product to be subject to the jurisdiction of the Food and Drug Administration as a drug. FDA, 1988. (Food and Drug Administration docket No 88P-0155.)

31 Food and Drug Administration. Letter from Daniel L Michels, Director, Office of Compliance, Center for Drugs and Biologics, to J Philip Ray, Advanced Tobacco Products, Inc. (San Antonio, TX) 1987 Feb 9.

32 Food and Drug Administration. Letter from Daniel $I$ Michels, Director, Office of Compliance, Center for Drugs and Biologics, to L Douglas Keeney, CA Blockers Inc (Louisville, KY) 1989 April 14

33 Food and Drug Administration. Letter from Richard Ronk, acting director, Center for Food Safety and Applied Nutrition, to Sutart Pape, Patton, Boggs and Blow (Washington, DC) 1987 Sept 16.

34 Trial Testimony of Preston Leek. In: Horton $v$ America Tobacco, Case No 9050, Circuit of Holmes County, Mississippi.

35 HR 4350 and S-2298, 102nd Congress of the United States, 1992.

36 Roemer R. Legislative action to combat the world tobacco epidemic, 2nd ed. Geneva: Tobacco or Health Programme, World Health Organisation, 1992.

37 Action on Smoking and Health $v$ Harris, 655 F.2d 236 (DC Cir 1980).

38 Coalition on Smoking or Health. Petition to classify cigarette products which are manufactured, advertised, promoted and labelled with implied or direct claims that use of these products will suppress appetite and control use of these products will suppress appetite and control weight as "drugs" under the Food,
Act, Washington DC: 1992 Feb 27.

39 Coalition on Smoking or Health. Petition to classify Philip Morris' new cigarette brand, MERIT ULTIMA, "drug" under the Food, Drug and Cosmetic Act. Washington, DC: $1992 \mathrm{Feb} 27$ 